\title{
KAJIAN TENTANG METODE PERSAMAAN RICCATI PROYEKTIF
}

\author{
FITRI YESSI JAMI \\ Program Studi Magister Matematika, \\ Fakultas Matematika dan Ilmu Pengetahuan Alam, Universitas Andalas, \\ Kampus UNAND Limau Manis Padang, Indonesia. \\ email : fitriyessijami@gmail.com
}

\begin{abstract}
In this paper, we discuss the derivation and application of a projective Riccati equation method in solving nonlinear partial differential equations. We also study the mathematical aspects of the method and its limitations in some particular cases.

Kata Kunci: Nonlinear partial differential equations, projective Riccati equation method, dominant balance principle
\end{abstract}

\section{Pendahuluan}

Fenomena gelombang nonlinier dapat dijumpai pada masalah dinamika fluida, kinematika reaksi kimia, proses biologi sel dan molekuler, fisika optik dan sebagainya [8]. Dalam banyak kasus, fenomena tersebut dapat dimodelkan secara matematis oleh suatu persamaan diferensial parsial (PDP). Semakin meningkatnya kajian terhadap model-model persamaan diferensial parsial dalam menjelaskan fenomena gelombang nonlinier, membuat semakin berkembang pula metode-metode alternatif dalam menyelesaikan persamaan tersebut. Beberapa diantara metode yang populer digunakan adalah metode tanh, metode invers scatering, metode dekomposisi Adomian dan metode persamaan Riccati proyektif $[1,2]$.

Paper ini secara khusus akan mengkaji lebih detail penurunan dan penerapan metode persamaan Riccati proyektif dalam menyelesaikan persamaan diferensial parsial nonlinier. Metode ini digagas pertama kali oleh Conte dan Mussete pada tahun 1992 dalam menentukan solusi soliton pada beberapa persamaan diferensial parsial nonlinier [3]. Metode Conte dan Mussete ini selanjutnya dikembangkan lebih lanjut oleh Yan pada tahun 2003 dengan memperkenalkan bentuk umum dari persamaan Riccati proyektif [4]. Beberapa peneliti telah menggunakan teknik Yan ini untuk menyelesaikan banyak persamaan diferensial parsial nonlinier.

Di antara hasil-hasil penelitian tersebut, belum ada yang membahas aspek matematis dari metode persamaan Riccati proyektif dan keterbatasannya dalam beberapa kasus tertentu. Barulah pada tahun 2009, Du menjelaskan hal tersebut dengan lebih rinci dan menyatakan hasilnya dalam beberapa teorema [5]. Paper ini akan mengeksplorasi kembali kajian yang dibahas oleh Du tersebut. 


\section{Penurunan Metode Persamaan Riccati Proyektif}

\subsection{Konstruksi Awal}

Pandang bentuk umum persamaan diferensial parsial nonlinier berikut:

$$
N\left(U, U_{t}, U_{x}, U_{x x}, \cdots\right)=0 .
$$

Dalam hal ini akan ditinjau solusi gelombang berjalan

$$
U(x, t)=u(\xi), \quad \xi=\omega x+c t,
$$

dimana $\omega \neq 0$ menyatakan bilangan gelombang dan $c \neq 0$ menyatakan kecepatan gelombang. Dengan mensubstitusikan persamaan (2.2) ke persamaan (2.1) diperoleh persamaan diferensial biasa nonlinier berikut:

$$
M\left(u, u^{\prime}, u^{\prime \prime}, \cdots\right)=0 .
$$

\subsection{Metode Persamaan Riccati Proyektif}

Metode persamaan Riccati proyektif mengikuti langkah-langkah berikut [5]:

Langkah 1. Nyatakan solusi dari persamaan (2.3) dalam bentuk

$$
u(\xi)=H_{1}(f)+g H_{2}(f),
$$

dimana

$$
H_{1}(f)=\sum_{i=0}^{m_{1}} b_{i} f^{i},
$$

dan

$$
H_{2}(f)=\sum_{i=0}^{m_{2}} c_{i} f^{i},
$$

dengan $f=f(\xi)$ adalah solusi dari persamaan persamaan Riccati proyektif

$$
\begin{gathered}
f^{\prime}=f g \\
g^{2}=F(f)=\sum_{i=0}^{m_{3}} a_{i} f^{i}, \quad g^{\prime}=\frac{1}{2} F^{\prime}(f) f,
\end{gathered}
$$

dimana $m_{1}, m_{2}$ dan $m_{3}$ adalah bilangan bulat positif.

Dengan menggunakan aturan rantai terhadap persamaan (2.4) diperoleh

$$
u^{\prime}(\xi)=H_{1}^{\prime}(f) f^{\prime}+g H_{2}^{\prime}(f) f^{\prime}+g^{\prime} H_{2}(f) .
$$

Dengan mensubstitusikan persamaan (2.7) dan (2.8) ke persamaan (2.9), diperoleh

$$
u^{\prime}(\xi)=H_{1}^{\prime}(f) f g+\frac{1}{2} F^{\prime}(f) f H_{2}(f)+H_{2}^{\prime}(f) f F(f) .
$$

Lebih lanjut, turunan kedua dari $u(\xi)$ diberikan oleh

$$
\begin{aligned}
u^{\prime \prime}(\xi)= & H_{1}^{\prime \prime}(f) f^{\prime} f g+H_{1}^{\prime}(f) f^{\prime} g+H_{1}^{\prime}(f) f g^{\prime}+\frac{1}{2} F^{\prime \prime}(f) f^{\prime} f H_{2}(f)+\frac{1}{2} F^{\prime} \\
& (f) f^{\prime} H_{2}(f)+\frac{1}{2} F^{\prime}(f) f H_{2}^{\prime}(f) f^{\prime} .
\end{aligned}
$$


Dengan menggunakan persamaan (2.7) dan (2.8), persamaan (2.11) menjadi

$$
\begin{aligned}
u^{\prime \prime}(\xi)= & H_{1}^{\prime \prime}(f) F(f) f^{2}+H_{1}^{\prime}(f) F(f) f+\frac{1}{2} H_{1}^{\prime}(f) F^{\prime}(f) f^{2}+\frac{1}{2} H_{2}(f) \\
& F^{\prime \prime}(f) f^{2} g+\frac{1}{2} F^{\prime}(f) H_{2}^{\prime}(f) f^{2} g+\frac{3}{2} F^{\prime}(f) H_{2}^{\prime}(f) f^{2} g+H_{2}^{\prime \prime}(f) \\
& f^{2} g F(f)+H_{2}^{\prime}(f) f g F(f) .
\end{aligned}
$$

Dengan cara serupa, $u^{\prime \prime \prime}(\xi), u^{(4)}(\xi)$ dan seterusnya dapat dicari.

Dengan mensubstitusikan persamaan (2.4), (2.7), (2.10) dan (2.11) ke persamaan (2.3) dan dengan menggunakan persamaan (2.7) dan(2.8), dihasilkan persamaan berikut:

$$
G_{1}(f)+g G_{2}(f)=0
$$

dimana $G_{1}(f)$ dan $G_{2}(f)$ adalah fungsi polinomial dalam $f$.

Langkah 2. Berdasarkan prinsip dominant balance, dapat ditentukan hubungan yang berlaku untuk $m_{1}, m_{2}, m_{3}$ sehingga nilai-nilai $m_{1}, m_{2}, m_{3}$ yang mungkin dapat ditentukan.

Langkah 3. Dengan menetapkan koefisien dari semua suku berdasarkan pangkat $f$ dalam $G_{1}(f)$ dan $G_{2}(f)$ bernilai nol, akan diperoleh sistem persamaan aljabar yang darinya dapat ditentukan nilai $a_{i}\left(i=0,1,2, \cdots, m_{3}\right), b_{i}\left(i=0,1,2, \cdots, m_{1}\right)$ dan $c_{i}\left(i=0,1,2, \cdots, m_{2}\right)$. Meskipun demikian, sistem yang diperoleh mungkin saja tidak mempunyai solusi. Hal ini berarti persamaan (2.3) tidak dapat diselesaikan oleh metode persamaan Riccati proyektif ketika menggunakan nilai $m_{1}, m_{2}, m_{3}$ yang diperoleh pada Langkah 2.

Langkah 4. Dengan mengkuadratkan kedua ruas persamaan (2.7), persamaan (2.8) menjadi

$$
\left(f^{\prime}\right)^{2}=f^{2} F(f)
$$

Perhatikan bahwa persamaan (2.14) dapat direduksi menjadi bentuk integral sebagai berikut:

$$
\begin{aligned}
\frac{d f}{d \xi} & = \pm f \sqrt{F(f)} \\
\int d \xi & = \pm \int \frac{d f}{f \sqrt{F(f)}} \\
\xi-\xi_{0} & = \pm \int \frac{d f}{f \sqrt{F(f)}} .
\end{aligned}
$$

Langkah 5. Dengan mensubstitusikan $a_{i}\left(i=0,1,2, \cdots, m_{3}\right)$ ke persamaan $(2.15)$ dan mengklasifikasikan akar-akar dari $F(f)$, maka persamaan (2.15) dapat diselesaikan sehingga diperoleh solusi eksak dari persamaan (2.14). Dengan demikian solusi eksak dari persamaan (2.3) juga dapat diperoleh. 


\section{Pembahasan}

Untuk mengilustrasikan secara singkat ide dari analisis yang akan dilakukan, di sini hanya akan dibahas bentuk khusus persamaan (2.3) sebagai berikut:

$$
u^{\prime \prime}+\alpha u^{\prime}=\sum_{i=0}^{k} d_{i} u^{i},
$$

dimana $\alpha, d_{i}(i=0,1,2, \cdots, k)$ adalah konstanta sebarang dan $k=(2,3,4)$. Contoh persamaan diferensial parsial yang dapat diturunkan menjadi persamaan (3.1) adalah persamaan Benjamin-Bona-Mahony (BBM)-Burgers yang diberikan oleh [6]:

$$
U_{t}-U_{x x t}-U_{x x}+U U_{x}=0 .
$$

Berdasarkan analisis prinsip dominant balance maka dapat ditentukan nilai-nilai yang mungkin untuk $m_{1}, m_{2}$ dan $m_{3}$. Sehingga untuk $k=2$ maka $m_{3}=m_{1}$ dan $m_{2} \leq \frac{m_{1}}{2}$. Sedangkan untuk $k=3$, maka $m_{1} \leq \frac{m_{3}}{2}$ dan $m_{2}=0$. Ketika $k=2$ maka persamaan (3.1) menjadi:

$$
u^{\prime \prime}+\alpha u^{\prime}=d_{0}+d_{1} u+d_{2} u^{2} .
$$

Sedangkan untuk $k=3$ maka persamaan (3.1) menjadi:

$$
u^{\prime \prime}+\alpha u^{\prime}=d_{0}+d_{1} u+d_{2} u^{2}+d_{3} u^{3} .
$$

Teorema 3.1. [5] Dengan menggunakan metode persamaan Riccati proyektif, persamaan (3.1) mempunyai solusi nontrivial setidaknya pada kasus berikut:

$$
\begin{aligned}
& \text { Kasus } 1: k=2, m_{3}=m_{1}=1, m_{2}=0 \\
& \text { Kasus } 2: k=3, m_{3}=2, m_{1}=1, m_{2}=0 .
\end{aligned}
$$

Bukti. Kasus 1: $k=2, m_{3}=m_{1}=1, m_{2}=0$.

Ketika $k=2$ maka persamaan (3.1) menjadi persamaan (3.3). Dengan mensubstitusikan persamaan (2.4), (2.10) dan (2.12) ke persamaan (3.3) dan dengan menggunakan persamaan (2.7) dan (2.8) dihasilkan persamaan berikut:

$$
\begin{aligned}
G_{1}(f)= & H_{1}^{\prime \prime}(f) f^{2} F(f)+H_{1}^{\prime}(f) f F(f)+\frac{1}{2} H_{1}^{\prime}(f) f^{2} F^{\prime}(f)+\frac{1}{2} \alpha F^{\prime}(f) f \\
& H_{2}(f)+\alpha H_{2}^{\prime}(f) f F(f)-d_{2}\left[H_{1}(f)\right]^{2}-d_{2} F(f)\left[H_{2}(f)\right]^{2}-d_{1} H_{1}(f) \\
& -d_{0}
\end{aligned}
$$

dan

$$
\begin{aligned}
G_{2}(f)= & \frac{1}{2} F^{\prime \prime}(f) H_{2}(f) f^{2}+\frac{1}{2} F^{\prime}(f) H_{2}(f) f+\frac{3}{2} F^{\prime}(f) H_{2}^{\prime}(f) f^{2}+H_{2}^{\prime \prime}(f) F(f) f^{2} \\
& +H_{2}^{\prime}(f) F(f) f+\alpha H_{1}^{\prime}(f) f-2 d_{2} H_{1}(f) H_{2}(f)-d_{1} H_{2}(f) .
\end{aligned}
$$

Dari Langkah 2 yang telah dilakukan, dapat dipilih $m_{3}=1, m_{2}=0$ dan $m_{1}=1$. Dengan mensubstitusikan $m_{1}=1$ ke persamaan (2.5) diperoleh

$$
H_{1}(f)=b_{1} f+b_{0} \text {. }
$$

Selanjutnya dengan mensubstitusikan $m_{2}=0$ ke persamaan (2.6) diperoleh

$$
H_{2}(f)=c_{0} \text {. }
$$


Terakhir dengan mensubstitusikan $m_{3}=1$ ke persamaan (2.8) diperoleh

$$
F(f)=a_{1} f+a_{0} .
$$

Dengan mensubstitusikan persamaan (3.7), (3.8) dan (3.9) ke persamaan (3.5) dan (3.6) serta berdasarkan Langkah 3, tetapkan koefisien dari semua suku berdasarkan pangkat $f$ dalam $G_{1}(f)$ dan $G_{2}(f)$ menjadi 0, sehingga diperoleh sistem persamaan aljabar berikut:

$$
\begin{aligned}
\frac{3}{2} b_{1} a_{1}-d_{2} b_{1}^{2} & =0, \\
b_{1} a_{0}+\frac{1}{2} \alpha a_{1} c_{0}-2 d_{2} b_{0} b_{1}-d_{2} a_{1} c_{0}^{2}-d_{1} b_{1}+\frac{1}{2} a_{1} c_{0}+\alpha b_{1}-2 d_{2} b_{1} c_{0} & =0, \\
d_{2} a_{0} c_{0}^{2}+d_{2} b_{0}^{2}+2 d_{2} b_{0} c_{0}+d_{1} b_{0}+d_{1} c_{0}+d_{0} & =0 .
\end{aligned}
$$

Dengan menggunakan Maple, solusi dari sistem persamaan di atas adalah

$$
\begin{aligned}
a_{1}= & \frac{2}{3} d_{2} b_{1} \\
a_{0}= & \frac{1}{3} d_{2} c_{0}\left(2 d_{2} c_{0}-\alpha+5\right)+2 d_{2} b_{0}-\alpha+d_{1} \\
d_{0}= & c_{0}^{2} d_{2}\left(-\frac{2}{3} c_{0}^{2} d_{2}+\frac{1}{3} \alpha c_{0} d_{2}-2 d_{2} b_{0}-\frac{5}{3} c_{0} d_{2}+\alpha-d_{1}\right)-d_{2} b_{0}\left(2 c_{0}-b_{0}\right) \\
& -d_{1} b_{0}-d_{1} c_{0} .
\end{aligned}
$$

Selanjutnya solusi persamaan (3.3) diberikan mengikuti bentuk persamaan (2.4), yaitu:

$$
u(\xi)=b_{1} f+b_{0} \pm c_{0} \sqrt{a_{1} f+a_{0}},
$$

dimana parameter $b_{1}, b_{0}, c_{0}, a_{1}$ dan $a_{0}$ memenuhi persamaan (3.10), (3.11) dan (3.12), sedangkan $f$ diperoleh dari penyelesaian persamaan integral (2.15), yaitu diberikan oleh

$$
\begin{aligned}
\pm \sqrt{a_{0}}\left(\xi-\xi_{0}\right) & =-2 \operatorname{arctanh}\left(\frac{\sqrt{a_{1} f+a_{0}}}{\sqrt{a_{0}}}\right) . \\
\Rightarrow f & =-\frac{a_{0}}{a_{1} \cosh ^{2}\left(\frac{1}{2} \sqrt{a_{0}}\left(\xi-\xi_{0}\right)\right)} .
\end{aligned}
$$

Kasus 2: Untuk $k=3$.

Maka persamaan (3.1) menjadi persamaan (3.4). Dengan mensubstitusikan persamaan (2.4), (2.10) dan (2.12) ke persamaan (3.4) dan dengan menggunakan persamaan (2.7) dan (2.8) dihasilkan persamaan berikut:

$$
\begin{aligned}
G_{1}(f)= & H_{1}(f) f^{2} F(f)+H_{1}^{\prime}(f) f F(f)+\frac{1}{2} H_{1}(f) f^{2} F^{\prime}(f)+\frac{1}{2} \alpha F^{\prime}(f) f H_{2}(f) \\
& +\alpha H_{2}^{\prime}(f) f F(f)-d_{3}\left[H_{1}(f)\right]^{3}-d_{2}\left[H_{1}(f)\right]^{2}-3 d_{3} F(f) H_{1}(f)\left[H_{2}(f)\right]^{2} \\
& -d_{2} F(f)\left[H_{2}(f)\right]^{2}-d_{1} H_{1}(f)-d_{0}
\end{aligned}
$$

dan

$$
\begin{aligned}
G_{2}(f)= & \frac{1}{2} F^{\prime \prime}(f) H_{2}(f) f^{2}+\frac{1}{2} F^{\prime}(f) H_{2}(f) f+\frac{3}{2} F^{\prime}(f) H_{2}^{\prime}(f) f^{2}+H_{2}^{\prime \prime} \\
& (f) F(f) f^{2}+H_{2}^{\prime}(f) F(f) f+\alpha H_{1}^{\prime}(f) f-3 d_{3}\left[H_{1}(f)\right]^{2} H_{2}(f)- \\
& d_{3} F(f)\left[H_{2}(f)\right]^{3}-2 d_{2} H_{1}(f) H_{2}(f)-d_{1} H_{2}(f) .
\end{aligned}
$$


Dari Langkah 2 yang telah dilakukan pada Subbab 3.1.2 dapat dipilih $m_{3}=2$, $m_{2}=0$ dan $m_{1}=1$. Dengan mensubstitusikan $m_{1}=1$ ke persamaan $(2.5)$ diperoleh

$$
H_{1}(f)=b_{1} f+b_{0} .
$$

Selanjutnya dengan mensubstitusikan $m_{2}=0$ ke persamaan (2.6) diperoleh

$$
H_{2}(f)=c_{0} \text {. }
$$

Terakhir dengan mensubstitusikan $m_{3}=2$ ke persamaan (2.8) diperoleh

$$
F(f)=a_{2} f^{2}+a_{1} f+a_{0} .
$$

Dengan mensubstitusikan persamaan (3.18), (3.19) dan (3.20) ke persamaan (3.16) dan (3.17) dan berdasarkan Langkah 3, tetapkan koefisien dari semua suku berdasarkan pangkat $f$ dalam $G_{1}(f)$ dan $G_{2}(f)$ menjadi 0, maka diperoleh sistem persamaan aljabar berikut:

$$
\begin{aligned}
2 a_{2} c_{0}-3 d_{3} b_{1}^{2} c_{0}-d_{3} a_{2} c_{0}^{3} & =0 \\
\frac{1}{2} c_{0} a_{1}+\alpha b_{1}-6 d_{3} b_{1} b_{0} c_{0}-d_{3} a_{1} c_{0}^{3}-2 d_{2} b_{1} c_{0} & =0 \\
3 d_{3} b_{0}^{2} c_{0}+d_{3} a_{0} c_{0}^{3}+2 d_{2} b_{0} c_{0}+d_{1} c_{0} & =0 \\
2 b_{1} a_{2}-d_{3} b_{1}^{3}-3 c_{0}^{2} d_{3} a_{2} b_{1} & =0 \\
\frac{3}{2} b_{1} a_{1}+\alpha a_{2} c_{0}-3 d_{3} b_{1}^{2} b_{0}-3 d_{3} c_{0}^{2} a_{2} b_{0}-3 d_{3} c_{0}^{2} a_{1} b_{1}-d_{2} b_{1}^{2}-d_{2} a_{2} c_{0} & =0 \\
b_{1} a_{0}+\frac{1}{2} \alpha c_{0} a_{1}-3 d_{3} b_{1} b_{0}^{2}-3 d_{3} c_{0}^{2} a_{0} b_{1}-3 d_{3} c_{0}^{2} a_{1} b_{0}-2 d_{2} b_{1} b_{0}-d_{2} a_{1} c_{0}^{2}-d_{1} b_{1} & =0 \\
d_{3} b_{0}^{3}+3 d_{3} c_{0}^{2} a_{0} b_{0}+d_{2} b_{0}^{2}+d_{2} a_{0} c_{0}^{2}+d_{1} b_{0}+d_{0} & =0 .
\end{aligned}
$$

Dengan menggunakan Maple, solusi dari sistem persamaan di atas adalah

$$
\begin{array}{r}
d_{3}=\frac{1}{2 c_{0}^{2}}, \quad d_{0}=\frac{d_{2} c_{0}^{2}\left(b_{0}^{2}-b_{1}^{2}\right)+b_{0}^{3}-b_{1}^{2} b_{0}}{c_{0}^{2}}, \\
a_{0}=\frac{b_{1}^{2}}{c_{0}^{2}}, \quad a_{2}=\frac{b_{1}^{2}}{c_{0}^{2}}, \\
\alpha=\frac{3 b_{0}+2 d_{2} b_{0}^{2}}{c_{0}}, \quad d_{1}=-\frac{4 d_{2} b_{0} c_{0}^{2}+3 b_{0}^{2}+b_{1}^{2}}{2 c_{0}^{2}} .
\end{array}
$$

Selanjutnya solusi persamaan (3.4) diberikan mengikuti bentuk persamaan (2.4), yaitu

$$
u(\xi)=b_{1} f+b_{0} \pm c_{0} \sqrt{a_{2} f^{2}+a_{1} f+a_{0}},
$$

dimana parameter $b_{0}, b_{1}, c_{0}, a_{2}, a_{1}$ dan $a_{0}$ memenuhi persamaan (3.21), (3.22) dan (3.23), sedangkan $f$ diperoleh dari penyelesaian persamaan integral (2.15), yaitu

$$
\pm\left(\xi-\xi_{0}\right)=\int \frac{d f}{f \sqrt{a_{2} f^{2}+a_{1} f+a_{0}}} .
$$

Teorema 3.2. [5] Dengan menggunakan metode persamaan Riccati proyektif, persamaan (3.1) hanya mempunyai solusi trivial setidaknya pada kasus $k=3$, $m_{3}=3, m_{1}=1, m_{2}=0$. 
Bukti. Ketika $k=3$, persamaan (3.1) menjadi persamaan (3.4), dengan mensubstitusikan persamaan (2.4), (2.10) dan (2.12) ke persamaan (3.4) dan dengan menggunakan persamaan (2.7) dan (2.8) diperoleh persamaan (3.16) dan (3.17). Dari Langkah 2, dapat dipilih $m_{3}=3, m_{2}=0$ dan $m_{1}=1$. Dengan mensubstitusikan $m_{1}=1$ ke persamaan (2.5) diperoleh

$$
H_{1}(f)=b_{1} f+b_{0} .
$$

Selanjutnya dengan mensubstitusikan $m_{2}=0$ ke persamaan (2.6) diperoleh

$$
H_{2}(f)=c_{0} .
$$

Terakhir dengan mensubstitusikan $m_{3}=3$ ke persamaan (2.8) diperoleh

$$
F(f)=a_{3} f^{3}+a_{2} f^{2}+a_{1} f+a_{0} .
$$

Dengan mensubstitusikan persamaan (3.26), (3.27) dan (3.28) ke persamaan (3.16) dan (3.17) dan berdasarkan Langkah 3, tetapkan koefisien dari semua suku berdasarkan pangkat $f$ dalam $G_{1}(f)$ dan $G_{2}(f)$ menjadi 0, maka diperoleh sistem persamaan aljabar berikut:

$$
\begin{aligned}
& \frac{9}{2} a_{3} c_{0}-d_{3} a_{3} c_{0}^{3}=0, \\
& 2 a_{2} c_{0}-3 d_{3} b_{1}^{2} c_{0}-d_{3} a_{2} c_{0}^{3}=0, \\
& \frac{1}{2} a_{1} c_{0}+\alpha b_{1}-6 d_{3} b_{1} b_{0} c_{0}-d_{3} c_{0}^{3} a_{1}-2 d_{2} b_{1} c_{0}=0, \\
& 2 d_{2} b_{0} c_{0}+d_{1} c_{0}+3 d_{3} b_{0}^{2} c_{0}+d_{3} c_{0}^{3} a_{0}=0, \frac{5}{2} b_{1} a_{3}-3 d_{3} a_{3} b_{1} c_{0}^{2}=0, \\
& 2 b_{1} a_{2}+\frac{3}{2} \alpha c_{0} a_{3}-d_{3} b_{1}^{3}-3 d_{3} a_{3} b_{0} c_{0}^{2}-3 d_{3} a_{2} b_{1} c_{0}^{2}-d_{2} a_{3} c_{0}^{2}=0, \\
& \frac{3}{2} b_{1} a_{1}+\alpha a_{2} c_{0}-3 d_{3} b_{0} b_{1}^{2}-3 d_{3} a_{2} b_{0} c_{0}^{2}-3 d_{3} a_{1} b_{1} c_{0}^{2}-d_{2} b_{1}^{2} \\
&-d_{2} a_{2} c_{0}^{2}=0, \\
& b_{1} a 0+\frac{1}{2} \alpha a_{1} c_{0}-3 d_{3} b_{1} b_{0}^{2}-3 d_{3} a_{1} b_{0} c_{0}^{2}-3 d_{3} a_{0} b_{1} c_{0}^{2}-2 d_{2} b_{1} b_{0} \\
&-d_{2} a_{1} c_{0}^{2}-d_{1} b_{1}=0, \\
& d_{3} b_{0}^{3}+3 d_{3} a_{0} b_{0} c_{0}^{2}+d_{2} b_{0}^{2}+d_{2} a_{0} c_{0}^{2}+d_{1} b_{0}+d_{0}=0 .
\end{aligned}
$$

Dari persamaan (3.29) dan (3.33) diperoleh $c_{0}=0$ atau $a_{3}=0$ atau $b_{1}=0$. Akibatnya semua parameter bernilai nol. Dengan demikian persamaan (3.1) hanya memiliki solusi trivial dengan metode persamaan Riccati proyektif ketika $k=3$ dan $m_{3}=3, m_{1}=1, m_{2}=0$.

Teorema 3.3. [5] Jika $k=4$, maka persamaan (3.1) tidak dapat diselesaikan dengan metode persamaan Riccati proyektif.

Bukti. Jika $k=4$, maka persamaan (3.1) menjadi

$$
u^{\prime \prime}+\alpha u^{\prime}=d_{0}+d_{1} u+d_{2} u^{2}+d_{3} u^{3}+d_{4} u^{4} .
$$


Berdasarkan analisis prinsip dominant balance, maka dapat disimpulkan bahwa berapapun nilai $m_{1}, m_{2}, m_{3}$ yang dipilih dari bilangan bulat nonnegatif, orde tertinggi suku turunan dan orde tertinggi suku nonlinier tidak dapat balance. Dengan demikian, solusi persamaan (3.1) tidak dapat diperoleh dengan menggunakan metode persamaan Riccati proyektif.

\section{Kesimpulan}

Pada paper ini telah dijelaskan penurunan dan penerapan metode persamaan Riccati proyektif dalam menyelesaikan persamaan diferensial parsial nonlinier. Disamping itu dijelaskan juga aspek matematis dari metode tersebut dan keterbatasannya dalam berbagai kasus tertentu.

\section{References}

[1] B., Li, dan Y., Chen. 2003. Nonlinear Partial Differential Equation Solved by Projective Riccati Equations Ansatz. Z. Natuforsch, 58a. 511-519.

[2] Wang, Zhen dan Zhang, Hong-Qing. 2006. New Exact Solutions to Some Difference Differential Equations. Chinese Physics 15 : 2210 - 2215.

[3] Conte,R. dan Mussete, M. 1992. Link Between Solitary Waves and Projective Riccati Equation. J. Phys. A 25 : 5609.

[4] Yan, Z. 2003. Generalized Method and It's Application in the Higher-order Nonlinear Schrödinger Equation in Nonlinear Optical Fitres, Chaos, Solitons and Fractals 16 : 759.

[5] Du, Xianghua. 2009. Some Notes on Projective Riccati Equation Method. FIZIKA A 18 Vol 4, $153-164$

[6] Mei, Ming dan Schmeiser, Christian. 2001. Asymptotic Profiles of Solutions for the BBM-Burgers Equation. Funkcialaj Ekvacioj. 44 : 151 - 170

[7] Liu, Cheng-Shi. 2009. The Exact Solution to Lienard Equation with High-Order Nonlinear Term and Applications. FIZIKA A 18. Vol 1, $29-44$

[8] Wang, Deng-Shang dan Li, Hongbong. 2008. Single and Multi Solitary Wave Solutions to a Class of Nonlinear Evolution Equations. Mathematical Analysis and Applications 343 : $273-298$. 